\title{
ENVIRONMENTAL SUSTAINABILITY IN THE PHARMACEUTICAL INDUSTRY
}

\author{
Suman Sharma and Alba Tiley ${ }^{1}$
}

\section{Introduction}

In the context of climate change as the biggest human health hazard of the twenty-first century (Costello et al., 2009), the pharmaceutical industry needs to ensure that the impact of climate change on health is better understood, and to evaluate its role and responsibilities towards the mitigation of risks associated with climate change. It is important to note that climate change alleviation and public health improvement are mutually reinforcing. This chapter will:

1. Highlight the impact of climate change on the pharmaceutical industry and the role played by the industry in mitigating risks of climate change by adopting responsible measures of production.

2. Use a case study on Centrient Pharmaceuticals to demonstrate the proven benefits of climate-friendly processes on the environment.

3. Explore the connections between irresponsible manufacturing practices and Antimicrobial Resistance (AMR), and the burden on climate change due to AMR.

4. Offer policy recommendations to pave the way for ethical practices aimed at establishing climate resilience.

\section{The effect of climate change on the pharmaceutical industry}

With climate change high on the global agenda, industries across sectors are setting clear environmental sustainability goals and are linking it to a vision for long-term business viability. The pharmaceutical sector has a significant role to play in achieving the Sustainable Development Goal 13 of tackling climate change by reducing greenhouse gas emissions, including reductions in energy use, and overall increased use of renewable energy. A few companies have already pledged to achieve carbon neutrality by investing in renewable energy and through internal energy management programmes. Others in the sector have begun to explore innovative models that qualify 
as climate compliant with an aim to improve water and energy efficiency, reduce waste footprints and limit the lifecycle impacts of products by focusing on materials, packaging and design.

The total global emissions of the pharma sector amounted to about 52 megatons of $\mathrm{CO}_{2}$ in 2015 (Belkhir and Elmeligi, 2019). The pharmaceutical industry's carbon emissions might not match those of heavy manufacturing industries and the energy sector, but various global studies have demonstrated the strong need for the pharma sector to step up and make concerted efforts to reduce carbon emission and to manage effluent discharge systems that pollute water and land resources, causing a huge threat to public health.

The need to reduce emissions and provide long-term reduction by global pharma companies are linked to legally binding international treaties on climate change mitigation such as the 2016 Paris Climate Change agreement. One study deduced that by 2025 , the overall pharma sector would need to reduce its emissions intensity by about 59\% from 2015 levels to adhere to the commitments as per the Paris Agreement (Belkhir, 2019).

For the pharma sector, the impact of climate change is twofold - firstly, responding to the increased risk of emerging diseases and health concerns as a result of environmental damage and secondly, decarbonising its own manufacturing and operational processes to prevent worsening impact.

The global disease burden due to climate change is difficult to determine; consequently, research and development for the pharmaceutical sector remains a challenge. In addition, while changing weather patterns are not expected to lead to occurrences of a new disease, they are very likely to lead to disease proliferation in new geographical areas (Thissen, 2011).

Some pharmaceutical companies have been looking at the issue of climate change and environment impact holistically. One stated goal is water neutrality, which can be attained by assuming a multi-pronged strategy with the aim of reducing freshwater consumption within a manufacturing plant by following the principle of reduce, reuse and recycle; additionally, rainwater is harvested within the plant to counterbalance the outside freshwater use; and the consumption of freshwater is compensated for by investing in watershed projects beyond the boundary for sustainable water management.

\section{The importance of responsible production}

The indispensability of medicines has allowed pharma companies to go unquestioned when it comes to the environmental impact they cause. Although reducing greenhouse gas emissions is an important aspect of responsible production, there are additional aspects that are also equally crucial. Two examples are the emissions of pharmaceuticals substances into the environment and product stewardship.

According to a literature review in Environmental Toxicology and Chemistry, it was found that 631 different pharmaceutical substances have 
been detected in the environment of 71 countries spread over each and every continent (aus der Beek et al., 2016). The review cited the example of the anti-inflammatory drug diclofenac, which has been detected in environmental matrices in 50 countries, and concentrations found in several locations exceeded predicted no-effect concentrations.

Hence, aspects like Extended Producer Responsibility (EPR), also known as Product Stewardship, should be adopted by pharma companies in addition to the quality aspects; sustainability should be woven in at all stages of production, procurement, and consumption (Box 19.1). It should also include the aspects of sustainable packaging and disposal.

\section{Box 19.1 Case study}

\section{Centrient Pharmaceuticals: Developing climate-friendly processes}

Sustainability and climate change is an area where the private sector can develop innovative solutions to global challenges by using their core competencies.

In 2012, Centrient Pharmaceuticals developed an enzymatic process known as PureActives ${ }^{\circledR}$ technology which reduces the number of production process steps - by more than $50 \%$ in some cases - thereby reducing the use of energy, water and raw materials. Traditional betalactam antibiotic manufacturing methods consist of 13 steps, with each step having a considerable impact on the environment.

The enzymatic technology allows the customers to significantly reduce their environmental footprint while also removing the use of aggressive solvents. During the PureActives ${ }^{\circledR}$ process, Centrient uses its own enzymes to alter the molecules and couple the side chain to make 6-APA or 7-ADCA molecules. In contrast with traditional chemical production processes, all of this takes place at ambient temperatures which require less energy, and moreover, it is done without the use of toxic solvents. Therefore, the impact of production on human health, as well as on the broader environment, is substantially lower.

These natural processes adopted by Centrient Pharmaceuticals have proven benefits when it comes to reducing the burden on the environment. The in-house Life Cycle Assessment (LCA) which evaluates environmental impacts throughout the entire life cycle of a product (production, use and discarding phases) demonstrates that the PureActives ${ }^{\circledR}$ technology results in a $63 \%$ reduction in the carbon footprint as compared to the traditional chemical method.

Source: Centrient, 2017 


\section{The linkage between irresponsible manufacturing of pharmaceuticals and antimicrobial resistance (AMR)}

A critical aspect that needs to be called out is the spread of antimicrobial resistance from the untreated effluent of pharma companies. Antimicrobial resistance (AMR) is essentially the ability of a microbe (bacteria, fungi, etc.) to resist the effects of medication that could once successfully treat the disease; AMR arises when bacteria become resistant to the antibiotic due to unnecessary exposure, rendering the antibiotic useless. In such cases, the illness caused by the bacteria becomes difficult or even impossible to treat. Drug resistance has the potential to endanger both developed and developing countries alike (IACG, 2019). Based on broad estimates, in addition to the costs associated with the loss of human lives, AMR has the potential to bring about a loss of $2-3.5 \%$ of global GDP, which could amount to USD 100 trillion by 2050 (Jonas et al., 2017).

AMR is emerging as one of the largest challenges to public health. In fact, in January 2020, the World Health Organization identified AMR as one of the top health priorities for the next decade (WHO, 2020). Lifesaving medical procedures which use antibiotics (such as joint replacement, cancer chemotherapy and organ transplantation) are becoming riskier to perform, and common diseases are turning unresponsive to treatment due to alarming levels of resistance reported in countries of all income levels. AMR-induced drug-resistant diseases claim the lives of over 700,000 people globally each year; without effective action, this number is set to reach 10 million by 2050, with almost a fifth of fatalities occurring in India (Jonas et al., 2017).

Countries such as India and China are at immediate higher risk as $80 \%$ of the antibiotics sold by multinational pharmaceutical companies globally are manufactured in these two countries. A June 2016 on-the-ground study by British investigative media agency Ecostorm and the subsequent analysis of water samples by Dr. Mark Holmes of the University of Cambridge found high levels of drug-resistant bacteria at sites in three Indian cities: Hyderabad, New Delhi and Chennai. In total, out of 34 sites tested, 16 were found to be harbouring bacteria resistant to antibiotics.

Box 19.2 discusses the formation of the AMR Industry Alliance.

\section{Box 19.2 Case study}

\section{AMR Industry Alliance: Industry initiative solving the environmental challenge}

In 2016, the United Nations called for a collaborative initiative from governments and various sectors to tackle the effects of antimicrobial resistance in a comprehensive manner and to implement strategies at the national level. The AMR Industry Alliance is the pharmaceutical 
industry's response to the appeal by the United Nations (Changing Markets and Ecostorm, 2016).

Accordingly, the AMR Industry Alliance's member companies made commitments to decrease the environmental impact resulting from the production of antibiotics. The Alliance aims to help eliminate or substantially reduce antibiotic residues in manufacturing discharges. The focus is particularly on ensuring better management of waste as well ensuring rigorous processes to minimise accidental spills and releases.

In early 2018, the AMR Alliance published the Common Manufacturing Framework which specified a set of minimum environmental expectations for antibiotic manufacturers. It also established science-driven, risk-based quantitative effluent discharge targets which apply to all types of factories that make antibiotics. The Framework is currently being implemented at all member companies across their supply chains (AMRIA, 2018).

This case study emphasises how responsible pharmaceutical/life science companies try to voluntarily opt for greener methods, keeping in mind the environmental aspect.

\section{The linkage between climate change and AMR}

A 2018 study explored the role of climate (temperature) and additional factors on the distribution of antibiotic resistance across the United States. The findings indicated that an increase in temperature of $10^{\circ} \mathrm{C}$ across regions was associated with an increase in antibiotic resistance of $4.2 \%, 2.2 \%$, and 2.7\% for the common pathogens Escherichia coli, Klebsiella pneumonia, and Staphylococcus aureus. The associations between temperature and antibiotic resistance within the ecological study were consistent across most classes of antibiotics and pathogens and may be strengthening over time (MacFadden et al., 2018). These findings suggest that current forecasts of the burden of antibiotic resistance might be significant underestimates within the face of a growing population and global climate change (O'Neill, 2016).

Another study investigated whether the explanatory strength of climate variables holds true in a region with diverse healthcare systems and societies and whether a global climate change dimension is identified, using Europe as a case region. The researchers conducted a 30-country observational study across Europe. The six-year prevalence of carbapenem-resistant Pseudomonas aeruginosa (CRPA), Klebsiella pneumonia (CRKP), multiresistant Escherichia coli (MREC), and Methicillin-resistant Staphylococcus aureus (MRSA) was determined based on data published by the European Centre for Disease Prevention and Control (ECDC). The authors cited that findings reveal a novel association between AMR and climatic factors in Europe. These results reveal two aspects: climatic factors significantly 
contribute to the prediction of AMR in several sorts of healthcare systems and societies, while global climate change might increase AMR transmission and carbapenem resistance (Kaba et al., 2020).

In May 2019, the World Health Organization (WHO) released a draft document on the environmental aspects of good manufacturing practices (GMP) to aid inspectors and manufacturers of antimicrobials in the prevention of antimicrobial resistance (AMR). The draft proposes ways to control and reduce the contamination of the environment with antimicrobials and chemicals from production processes, as part of WHO's response to the growing threat of AMR (WHO, 2019).

Hence, it is imperative for pharma companies to adhere to responsible manufacturing to lower the rate of spread of drug resistance.

\section{Reporting}

As per a study done in 2018 , more than 200 companies represent the global pharmaceutical market, yet only 25 consistently reported their direct and indirect greenhouse gas emissions in the past five years. Of those, only 15 reported their emissions since 2012 (Lotfi and Elmeligi, 2019). This further reiterates that not all pharma firms are transparent about their environmental practices; however, there are at least a few who are setting practical examples for others to follow. The pharma industry needs to follow the example of other industries to become more transparent regarding the protection of the environment.

\section{Recommendations}

Looking at the urgency with which the issue should be tackled, the following initiatives are recommended:

1. Setting science-based targets: To start with, it will be useful to link environmental targets to the Paris Agreement goals. For example, this can be done by aligning with the Science-Based Targets Initiative - a platform that encourages companies to commit to staying within a safe range for carbon emissions. This can be made stronger by encouraging companies to report carbon emissions in a more transparent manner.

2. Allocating responsibility across the value chain: Buyers of pharmaceutical products including government agencies can use their purchasing power to influence the industry by valuing sustainability factors (e.g. climate impact and AMR impact) when making procurement decisions. 
3. Assign Accountability: The prevailing production, distribution and marketing practices of pharmaceutical companies need to be periodically reviewed. Governments may award economic incentives to entities that follow sustainable measures and carry out appropriate waste management, including effluent discharge. In the same vein, existing incentives should be withdrawn from those who are found to be non-compliant.

4. Higher investments: Serious efforts should be made to implement the One Health approach by exploring innovative means and alternatives and increasing funding for promotion, affordable access and research on antimicrobials, diagnostics, vaccines, waste management tools, and safe and effective alternatives to antimicrobials.

5. Greater collaborative efforts: Multisectoral efforts involving civil society groups is essential in order to respond to AMR challenges. Closer engagement with stakeholders such as professional societies (medical and veterinary), NGOs, farmers' associations, research networks and academia, will be helpful in advocacy efforts, generating awareness and ensuring transparency of governance and monitoring.

\section{Key takeaways}

- The pharmaceutical industry must adopt responsible measures of production to mitigate their role in causing climate change.

- Irresponsible manufacturing practices and Antimicrobial Resistance (AMR) have increased the burden of climate change from the pharma industry.

- There is a need for government as well as pharmaceutical companies to understand the interface between people, health, environment, and their own operations.

- The full value chain - from manufacturer and distributor to user - must be involved in order to ensure sustainable buying and procurement

- It is crucial for the pharmaceutical industry to learn from best practices in other industries and work collaboratively with governments and other relevant stakeholders to create a conducive ecosystem that contributes positively to public health.

\section{Note}

1 With thanks to Chase India for research support provided.

\section{References}

AMR Industry Alliance Secretariat. (2018). Making antibiotics responsibly: A common antibiotic manufacturing framework to tackle AMR. AMRIA. https://www. amrindustryalliance.org/wp-content/uploads/2019/11/Making-antibioticsresponsibly_A-common-manufacturing-framework-to-tackle-AMR.pdf 
aus der Beek, T., Weber, F. A., Bergmann, A., Hickmann, S., Ebert, I., Hein, A., \& Küster, A. (2016). Pharmaceuticals in the environment. Global occurrences and perspectives. Environmental Toxicology and Chemistry, 35(4), 823-835. doi: 10.1002/etc.3339

Belkhir, L. (2019, May 28). Big pharma emits more greenhouse gases than the automotive industry. McMaster University. https://brighterworld.mcmaster.ca/articles/ big-pharma-emits-more-greenhouse-gases-than-the-automotive-industry/

Belkhir, L., \& Elmeligi, A. (2019). Carbon footprint of the global pharmaceutical industry and relative impact of its major players. Journal of Cleaner Production, 214. doi: 10.1016/j.jclepro.2018.11.204.

Centrient. (2017). Centrient pharmaceuticals sustainability report 2017. Centrient Pharmaceuticals Global Communications. https://Centrient_SustainabilityReport _2017_web.pdf

Changing Markets and Ecostorm. (2016). Superbugs in the supply chain: How pollution from antibiotics factories in India and China is fueling the global rise of drug-resistant infections. Changing Markets. https:/epha.org/wp-content/ uploads/2016/10/Superbugsinthesupplychain_CMreport.pdf

Costello, A., Abbas, M., Allen, A., Ball, S., Bell, S., Bellamy, R., Friel, S., Groce, N., Johnson, A., Kett, M., Lee, M., Levy, C., Maslin, M., McCoy, D., McGuire, B., Montgomery, H., Napier, D., Pagel, C., Patel, J., de Oliveira, J. A., Redclift, N., Rees, H., Rogger, D., Scott, J., Stephenson, J., Twigg, J., Wolff, J., \& Patterson, C. (2009). Managing the health effects of climate change: Lancet and University College London Institute for Global Health Commission. Lancet, 373(9676), 1693-1733. doi: 10.1016/S0140-6736(09)60935-1. Erratum in: (2009, June 27). Lancet, 373(9682), 2200. PMID: 19447250.

IACG. (2019, April). No time to wait: Securing the future from drug-resistant infections Report to the Secretary-General of the United Nations by the Interagency Coordination Group on Antimicrobial Resistance. https://cdn.who.int/media/ docs/default-source/documents/no-time-to-wait-securing-the-future-from-drugresistant-infections-en.pdf?sfvrsn=5b424d7_6\&download=true

Jonas, O. B., Irwin, A., Berthe, F. C. J., Le, G., Francois, G., \& Marquez, P. V. (2017). Drug-resistant infections: A threat to our economic future (Vol. 2): Final report (English). HNP/Agriculture Global Antimicrobial Resistance Initiative. World Bank Group.http://documents.worldbank.org/curated/en/323311493396993758/ final-report

Kaba, H. E. J., Kuhlmann, E., \& Scheithauer, S. (2020). Thinking outside the box: Association of antimicrobial resistance with climate warming in Europe - A 30 country observational study. International Journal of Hygiene and Environmental Health, 223(1), 151-158. doi: 10.1016/j.ijheh.2019.09.008

MacFadden, D. R., McGough, S. F., Fisman, D., Santillana, M., \& Brownstein, J. S. (2018). Antibiotic resistance increases with local temperature. Nature Climate Change, 8, 510-514. doi: 10.1038/s41558-018-0161-6

O’Neill, J. (2016). Tackling drug-resistant infections globally: Final report and recommendations. HM Government and Wellcome Trust.

Thissen, E. (2011). Climate change and global health: The role for business. Sustainability Issue Brief, 3. 
WHO. (2019). Environmental aspects of good manufacturing practices: Points to consider for manufacturers and inspectors in the prevention of antimicrobial resistance. WHO Draft Working Document QAS/19-802. https://www.who.int/ medicines/areas/quality_safety/quality_assurance/qas19_802_environmental_ aspects_of_GMP.pdf?ua $=1$

WHO. (2020). Antimicrobial resistance. WHO factsheet. https://www.who.int/ news-room/fact-sheets/detail/antimicrobial-resistance 